\title{
Analysis of structure and deformation behavior of AISI 316L tensile specimens from the second operational target module at the Spallation Neutron Source
}

\author{
M. N. Gussev ${ }^{1}$, D. A. McClintock ${ }^{1}$, F. A. Garner ${ }^{2}$ \\ ${ }^{1}$ Oak Ridge National Laboratory, Oak Ridge, Tennessee, USA \\ ${ }^{2}$ Radiation Effects Consulting, Richland, Washington, USA \\ Corresponding Author, E-mail: mcclintockda@ornl.gov
}

Key words: Spallation Neutron Source, 316L stainless steel, neutron irradiation, proton irradiation, tensile behavior, deformation wave phenomenon, transformation induced plasticity (TRIP), phase transformation

\begin{abstract}
In an earlier publication, tensile testing was performed on specimens removed from the first two operational targets of the Spallation Neutron Source (SNS). There were several anomalous features in the results. First, some specimens had very large elongations (up to 57\%) while others had significantly smaller values (10-30\%). Second, there was a larger than the usual amount of data scatter in the elongation results. Third, the stress-strain diagrams of nominally similar specimens spanned a wide range of behavior ranging from expected irradiation-induced hardening to varying levels of force drop after yield point and indirect signs of "traveling deformation wave" behavior associated with strain-induced martensite formation. To investigate the cause(s) of such variable tensile behavior, several specimens from Target 2, spanning the range of observed tensile behavior, were chosen for detailed microstructural examination using electron backscatter diffraction (EBSD) analysis. It was shown that the steel employed in the construction of the target contained an unexpected bimodal grain size distribution, containing very large out-of-specification grains surrounded by "necklaces" of grains of within-specification sizes. The large grains were frequently comparable to the width of the gauge section of the tensile specimen. The propensity to form martensite during deformation was shown to be accelerated by radiation but also to be very sensitive to the relative orientation of the grains with respect to the tensile axis. Specimens having large grains in the gauge that were most favorably oriented for production of martensite strongly exhibited the traveling deformation wave phenomenon, while those specimens with less favorably oriented grains had lesser or no degree of the wave effect, thereby accounting for the observed data scatter.
\end{abstract}

(C) 2015. This manuscript version is made available under the Elsevier user license http://www.elsevier.com/open-access/userlicense/1.0/ 


\section{Introduction}

Neutrons at the Spallation Neutron Source (SNS) are produced by bombarding flowing liquid mercury with $1 \mathrm{GeV}$ protons at a frequency of $60 \mathrm{~Hz}$. Neutrons produced in the target module from proton-mercury spallation reactions are moderated to suitable energies prior to traveling down beam lines to neutron-scattering instruments. The mercury flowing through the target vessel functions as both the neutron-producing target material and the coolant. The SNS target module is a dual-vessel structure constructed from AISI 316L and consists of an inner mercury vessel, through which the mercury flows, surrounded by a water-cooled shroud that is designed to capture and contain mercury in the event of a leak. During $1 \mathrm{MW}$ operation the maximum temperature in the beam entrance region of the mercury vessel ranged from 150 to $180^{\circ} \mathrm{C}$, while the peak temperature in the water-cooled shroud was approximately $80-100^{\circ} \mathrm{C}$.

While neutron irradiation over a wide range of neutron flux-spectra is well known to alter the dimensional, physical and mechanical properties of 300 series stainless steels [1], irradiation in spallation-derived spectra can induce even greater alterations because it is an exceptionally energetic spectrum composed of both high-energy neutrons and high-energy protons. These high-energy particles not only produce atomic displacements and a very wide range of transmutant elements and radioactive isotopes, but also generate large amounts of helium and hydrogen [2-5]. Indeed, spallation-produced gas generation rates are much higher than those produced in most fission spectra and vary strongly with the local proton/neutron ratio in fluxspectra, which varies for different devices [1, 3].

While a large amount of high-dose mechanical property data have been generated in fast and thermal reactors, relatively few studies on radiation-induced changes in mechanical properties of austenitic steels derived from spallation sources (LANCSE, SINQ, SNS) have been published [616]. Of particular concern for the SNS, however, was the response of the mechanical properties of 316L to irradiation conditions prototypic of the SNS target spectrum. Therefore, a Post Irradiation Examination (PIE) campaign was established at the SNS to characterize the changes in mechanical properties of samples from SNS target modules after removal from service [17, 18].

Using annular cutters with carbide cutting teeth, $60 \mathrm{~mm}$ diameter disk-shaped specimens were removed from the beam entrance region of the first two operational SNS targets [17, 19], designated hereafter as Target 1 and Target 2. Various types of specimens were machined from the disks to examine the stability of the Kolsterising ${ }^{\circledR}$ treated layer on the target vessel surfaces exposed to mercury [20] and measure the tensile properties [21] for doses ranging from 4 to 7 displacements per atom (dpa). 
Though the majority of the tensile testing results were in agreement with hardening and loss-ofductility trends previously observed in 300 series alloys irradiated in spallation environments, there was rather large atypical scatter in the elongation data and at least one specimen reached an uncharacteristically large value of total elongation. Specifically, specimen D6-2 from Target 2, which was irradiated to $5.4 \mathrm{dpa}$, reached a total elongation of approximately $57 \%$ at failure. The load-displacement curve for this specimen also exhibited abnormal behavior relative to the other specimens tested from Targets 1 and 2; specifically a prompt load drop occurred after yielding followed by a long relatively flat plateau with a slight load drop prior to failure. The uncharacteristically large total elongation and rather peculiar shape of the load-displacement curve for this specimen could not be readily explained in the earlier paper, thus providing the motivation to conduct the microscopy work described in this paper.

\section{Experimental procedure}

Three previously tested tensile specimens, designated D1-2, D6-2, and D7-2, were chosen from the Target 2 testing campaign for detailed microscopic examination. These three specimens were taken from different layers of the beam entrance region of Target 2. D7-2 was removed from the inner guide wall of the water-cooled shroud, while D1-2 and D6-2 were removed from the inner and outer mercury vessel walls, respectively. The irradiation temperature of the steel in the SNS target material depends on beam power and location, but estimates for the irradiation temperatures experienced by the three specimens studied in this report fall within the $50-150^{\circ} \mathrm{C}$ range. D7-2 from the water-cooled shroud has a lower temperature range and the temperature ranges of D1-2 and D6-2 should be higher. The calculated displacement doses arising from combined proton and neutron irradiation were 3.8 dpa for D1-2 and 5.4 dpa for the other two specimens as reported earlier [21]. Unfortunately, there was no available unirradiated archive material of the heat used to build the target, so there is no knowledge of the starting unirradiated microstructure. For magnetic measurements, however, comparable steel in the same starting condition was employed.

The individual layers of the target, and therefore the disks from which the tensile specimens were cut, were fabricated from the same heat of 316L steel in the mill-annealed condition with the composition shown in Table 1.

Heat treatments were used to maintain dimensional stability throughout the fabrication process with the temperature not allowed to exceed $430^{\circ} \mathrm{C}$. The inner and outer windows of the mercury target vessel were treated with a Kolsterising ${ }^{\circledR}$ treatment to increase the surface hardness and inhibit cavitation-induced erosion [22], but this layer was removed during specimen machining and therefore did not influence the tensile test results. The tensile specimens (see [21] for specimen geometry) were tested at room temperature with a strain rate of approximately $10^{-3} \mathrm{~s}^{-1}$. 
The microstructures of the three tested tensile specimens were characterized using a combination of optical and electron microscopy. The gauge section of the each specimen was imaged using an optical microscope with side lighting to evaluate strain-induced relief on the specimen surfaces. Also, the gauge section thickness and width were measured for each specimen using several points along the gauge section length to calculate an estimate of the local strain level at each point, calculated as $\varepsilon_{\mathrm{L}}=\mathrm{S}_{0}{ }^{2} / \mathrm{S}_{\mathrm{i}}{ }^{2}-1$, where $\mathrm{S}_{0}$ and $\mathrm{S}_{\mathrm{i}}$ are pre- and post-strain cross-sectional area, respectively. Then a maximum true stress value $(\sigma)$ reached at this point, was calculated as $\sigma=$ $\mathrm{UTS} \times\left(1+\varepsilon_{\mathrm{L}}\right)$, where UTS is an ultimate tensile strength value for the corresponding specimen. Both these relationships are based on the "constant volume criteria”, assuming that the changes in material density and specimen shape (rectangular) are small and, therefore, can be neglected.

Prior to microstructural analysis, the gauge section of each tensile specimen was cut from the specimen head and the gauge sections were prepared using routine metallography procedures: mechanical grinding, polishing, and final electropolishing using a Struers electropolishing unit with Struers A2 solution. One tensile head of D6-2 was prepared and examined to provide a baseline representing the pre-test non-deformed structure.

Electron-backscatter diffraction (EBSD) analysis was performed on all specimens using a JEOL JSM 6500F microscope with a field emission gun, equipped with an OIM system by EDAX. The accelerating voltage was $20 \mathrm{kV}$ and the working distance varied from 11 to $12 \mathrm{~mm}$. The EBSD maps were measured on a hexagonal grid with a step size of 0.1 to $2 \mu \mathrm{m}$. The camera was run with a $1 \times 1$ binning mode. Each of the beam-scan fields was measured at a magnification of $5000 \mathrm{X}$ or more to ensure that all points were in focus.

EBSD data were filtered (minimum grain size 3 points, single iteration, maximum point-to-point misorientation $5^{\circ}$ ) to reduce indexation errors. Risks associated with the data filtering [23] were considered and believed to be negligible in the context of the present work. Also, image quality (IQ) maps were produced to obtain qualitative information about the microstructure of the deformed samples. The IQ maps describe the quality of the electron-backscattered patterns, which is related to the strain distribution in the microstructure [24]. The IQ map contrast clearly reveals microstructural details such as grains, twins, phase boundaries, and slip bands. It is important to emphasize that the grid step size limits the size of the structure elements that can be analyzed using EBSD. For example, if a 0.1- $\mu \mathrm{m}$ minimal step size is used, the object of interest (e.g., bcc [body centered cubic] phase particle, twins) should be larger than $\sim 0.2-0.3 \mu \mathrm{m}$ to be reliably observed. In many cases, the observation and identification of the smaller bcc-phase particles were confirmed by post-scanning manual analysis of the EBSD patterns.

It should be noted that examination of the SNS-irradiated specimens revealed a rather low pattern quality compared to typical in-reactor irradiated and/or deformed steels of similar composition. To provide acceptable pattern quality and ensure the correct identification of 
different phases, a scanning rate of 5-10 points per second was used which is 10 times slower compared to the ordinary scanning rate. Therefore, accumulated statistics was smaller than usual. The reason for low pattern quality in SNS-specimens is currently unknown. The surface preparation method was checked, and good surface quality was ensured. The necessity for a slow scan rate may be the result of a high density of radiation-induced black-dot defects characteristic of the low irradiation temperature experienced by these specimens. Increased plastic strain also leads to an additional decrease of the EBSD pattern quality, and thus for the necking area of the deformed specimens no reliable EBSD data were obtained.

To measure the amount of magnetic phase, a Fisher FMP-30 ferroprobe was employed. Prior to taking measurements, the device was calibrated with a three-level ferrite etalon set at $0.53 \%$, $2.96 \%$, and $10.4 \% \delta$-ferrite. This ferroprobe has a threshold limit of $0.1 \%$ of ferrite, and, therefore, any magnetic phase amount below this limit could not be reliably detected. The probe cannot distinguish between ferrite, which usually forms under irradiation, and other magnetic phases like strain-induced martensite. Also, the ferroprobe is sensitive to the specimen geometry (primarily thickness) and for the deformed SS-3 specimen the magnetometry data should include a scale factor correction. This consideration lies outside the present work scope, however. Therefore, the results will be given in "relative units" $\left(\mathrm{M}_{\mathrm{f}}\right)$ only. The magnetic phase amount measured at the irradiated specimen gauges was compared to the local strain level and therefore allowed for estimation of the amount of strain-induced martensite.

\section{Results and discussion}

\subsection{Specimen selection}

Tensile curves for the three selected specimens are shown in Fig. 1 and the corresponding displacement dose and mechanical properties are presented in Table 2 . The mechanical test results for the larger specimen matrix were reported elsewhere [21] and will not be discussed in detail in the present work. As was noted by McClintock and coworkers [21], the tensile tests revealed an unexpectedly high level of data scatter and the engineering tensile curves indicated that different types of deformation behavior occurred during testing. For instance, some specimens exhibited a pronounced force drop after yielding, and some specimens had smooth tensile curves with monotonic load increases. The most intriguing finding was the abnormally high total elongation experienced by specimen D6-2 during room temperature testing while simultaneously exhibiting essentially zero uniform elongation.

The first specimen examined was D6-2 and was chosen primarily because of its abnormally high ductility. Also, the tensile load-displacement curve for this specimen demonstrated unusual behavior: an extended S-shape in the curve associated with localized necking just before failure. Moreover, one half of the gauge section was noticeably longer and thinner than the other half, a 
behavior similar to specimens that have exhibited the "traveling deformation wave" [25-27] or TRIP effect [28]. The deformation wave phenomenon, previously studied in fast reactor steels by Gusev and coworkers, leaves in its wake very high levels of martensite that does not allow necking to produce flow localization and failure, thereby producing unexpectedly high levels of elongation, but producing a stronger and more brittle steel. The wave phenomenon is accelerated by lower test temperatures [27] and, as expected, progressively by increasing radiation exposure, especially when both the irradiation and the test are conducted at lower temperatures.

The second specimen examined was D1-2, which had a tensile diagram similar to D6-2, but with significantly lower elongation value. Both specimens demonstrated a pronounced force drop after the yield point. Specimen D7-2 was the third specimen chosen for detailed examination because, in contrast to the first two selected specimens, the load-displacement curve displayed no force drop after the yield point and had lower ductility with higher strength level compared to the other specimens. The small differences in calculated doses are not thought to account for these observed differences in mechanical behavior. Unfortunately, only one half of each tensile specimen was available for structure characterization in the current study, as the other halves were used previously to examine the fracture surfaces.

\subsection{Magnetic phase measurements}

Tensile specimens were machined from disk-shaped samples using electrical discharge machining (EDM) and were tested with the EDM recast layer still present on the specimen surfaces. This choice is justified since magnetic phase measurements were conducted using a ferroprobe on “as-received” specimens, with the EDM recast layer still present, and on specimens after mechanical grinding with EDM recast layer removed. The difference in ferroprobe readings was fairly small, and the results for as-received specimens are reported in the present work (Fig. 2). It was found that the non-deformed portion of the gauge contained some magnetic phase $\left(\mathrm{M}_{\mathrm{f}} \sim 0.15\right)$, whereas non-deformed and non-irradiated 316L steel (a stand-in substitute in absence of an archive) had no discernible magnetic phase.

The same measurements were conducted using the specimen heads, and the results were comparable. The measurements were repeated several times after mechanical grinding and electro-polishing to ensure there was no contribution from EDM-induced layer. Thus, it is believed that the magnetic phase measured in the non-deformed specimen material was formed during irradiation and may be either radiation-induced ferrite and/or martensite.

Formation of magnetic phases in 300-series steels has been observed and reported by numerous authors for a wide range of irradiated Fe-Cr-Ni steels and alloys by using magnetic properties [29-31] and by microscopy [32, 33]. The formation of radiation-assisted ferrite has been observed in specimens irradiated at the operational temperature of power reactors [34, 35] and 
martensite formation has been observed following low-temperature ion irradiation [36].

The amount of martensite in an irradiated specimen after ion irradiation may be significant. For instance, Johnson et al. [37] analyzed martensitic transformation in 304 steel irradiated with helium, hydrogen, and deuterium at $200^{\circ} \mathrm{C}$. The amount of martensite was estimated to be more than $30 \%$ after a helium ion fluence of $\sim 10^{22} \mathrm{~m}^{-2}$. Dodd and coworkers also observed extensive martensite formation in ion-irradiated Invar alloys arising from irradiation-driven spinodal-like decomposition of the alloy matrix [38].

Radiation-assisted formation of bcc-phase can impact material performance; for example, bccphases can increase the pit corrosion rate [39] or accelerate galvanic corrosion [40]. However, its impact on the material performance under SNS conditions is unclear at the moment.

During the EBSD analysis of the irradiated and non-deformed material of this study, no indications of bcc-phase were reliably observed, so the magnetic particles probably have a size below the EBSD resolution limit ( 100-200 nm). Further transmission electron microscopy (TEM) analysis is needed to establish the nature of the radiation-assisted magnetic phase; however, this is beyond the present work scope.

The amount of magnetic phase measured for a given heat was found to be proportional to the local strain value. As local strain increased, the amount of magnetic phase increased as well, reaching up to $\sim 2 \%$, as shown in Fig. 2 . The increased volume of magnetic phase is most likely explained by the formation of bcc-martensite during deformation, a proposition that is explored below using ESBD analysis.

It should be noted that magnetic probe has a diameter of $\sim 1 \mathrm{~mm}$ and reports an averaged (or "integral") readings for the specimen volume of comparable size; thus the probe cannot distinguish sharp changes in the magnetic phase profile occurring on scales smaller than $\sim 0.5-1$ $\mathrm{mm}$. However, specimens of the same geometry (thickness, width) may be accurately compared relative to each another.

As shown in Fig. 2, the magnetic phase increased in all specimens, but the D1-2 specimen demonstrated a slower onset of magnetic phase growth compared to other two specimens. It appears that some preliminary strain $(\sim 0.1-0.2)$ is required to produce martensite in the irradiated specimens, but this value is significantly less compared to the non-irradiated steel ( $\sim 0.5-0.6)$ of similar composition, suggesting that irradiation leads to a decrease in the critical strain level required to produce martensite, as discussed in [25].

\subsection{Structure of non-deformed material}


Fig. 3 shows the structure of the non-deformed material taken from the non-deformed head of specimen D6-2. Using SEM-EBSD, it was found that abnormally large grains were present in many areas of the specimen; a number of overlapping scans were performed trying to evaluate the size of the large grains. Grains as large as $2-2.5 \mathrm{~mm}$ were observed, but most large grains were below $1 \mathrm{~mm}$ in size.

Regular grains, of $\sim 180-200 \mu \mathrm{m}$ size, were found to occupy about half of the volume, suggesting a strong bimodal grain distribution. Interestingly, in most cases the abnormal grains were surrounded by bands or "necklaces" of regular size grains (Fig. 3). Only in very rare cases do two large grains share a common boundary. The large grains examined in these specimens contained significant internal misorientation as shown by gradual changes of color within a grain, reflecting local variation of orientation as seen in Fig. 3.

It is currently unclear what caused the formation of the large-grain bimodal grain structure. According to the certified material test report (CMTR) for the material used to fabricate Target 2 the grain size was measured and reported as grain size \#2 per ASTM E112, corresponding to an average grain diameter of approximately $180 \mu \mathrm{m}$. Grain growth in 316-series stainless steels occurs at temperatures above approximately $1,038^{\circ} \mathrm{C}\left(1,900^{\circ} \mathrm{F}\right)$, with most growth occurring in the first 15 minutes of exposure to elevated temperatures [41].

SNS Target 2 underwent two elevated temperature processes during fabrication: (1) dimensional stability heat treatments and (2) porosity repair using tungsten inert gas (TIG) welding. Dimensional stability treatments are performed on the target components throughout the fabrication process to satisfy the stringent dimensional requirements imposed by the target design. But dimensional stability treatments are conducted below $430^{\circ} \mathrm{C}$, which is well below the temperature required for appreciable grain growth. During the fabrication of the first SNS target vessel, centerline porosity was observed in the thick 316L plate material used for the front sections of the target [42], and TIG welding was utilized to repair the exposed pores. Though some grain growth might have occurred around welds, it is unlikely that the limited number of weld repairs caused the observed bimodal grain structure.

Others have investigated abnormal grain growth (AGG) in austenitic steels [43, 44]. In most cases, AGG required some plastic strain (a few percent) and subsequent annealing at 900$1100^{\circ} \mathrm{C}$. The resulting abnormal grains are expected to be $2-5$ times larger compared to the initial grain population, whereas in the present work the abnormal grains are 10 or more times larger. Also, necklaces of regular grains were not a common observation. Liu and Mayer reported grain growth under ion-induced irradiation [44], but usually this phenomenon was observed in ultrasmall grain materials or even in nano-structured materials or thin layers and a typical scale of grain growth was much below 1 micron [44]. 
How such large coarse grains influence the performance of the component under the SNSspecific conditions is an important technical question because cavitation-induced erosion is one of the key degradation mechanisms of the target and is influenced by grain size [18]. Decreases in grain size increase the strength and usually improves many performance metrics. Cavitationinduced wear was analyzed by Bregliozzi et al. [45] as a function of grain size, and it was concluded that a decrease in grain size improves the cavitation resistance. An investigation into the cause of the grain growth and its implications for target performance are ongoing.

At the same time, larger grain sizes may accelerate martensite accumulation and thus improve the strength. Iwamoto and Tsuta analyzed grain size role on martensite accumulation in 304 stainless steel [46]. For a grain size range of 22 to $142 \mu \mathrm{m}$, specimens with larger grains had more martensite compared to the specimens with smaller grains. It was suggested that the martensite accumulation, providing additional hardening, increased the acting true stress, which led to faster phase transformation. In other words, a positive feedback loop may exist between large grain size and martensite formation during deformation.

\subsection{Strain induced changes in dimension and surface appearance}

The gauge of the D6-2 tensile specimen is shown in Fig.4. Several features can be observed with the aid of side lighting: a pronounced deformation band close to the middle of the gauge and a neck region with an unusual elongated shape. The general appearance of these features is very similar to the case of "traveling deformation wave" discussed by Gusev and coworkers [25-27]. Also, as shown in [26], a significant portion of the gauge remained non-deformed and, therefore, the dimensional change in these portions was negligibly small. However, for the deformed portion of the gauge the level of local strain was significantly higher in the current study compared to that observed by in earlier studies (75-80\% vs. 30-40\% in [25], respectively), suggesting that most of the plastic strain occurred in the middle half of the gauge. The appearance of the surface also indicated that large grains were present, similar to the large grains observed in the non-deformed irradiated material.

Also, the abnormal grain shown in Area S1 (Fig. 4) demonstrated pronounced rotation towards this stable orientation (D); the prior-strain orientation is believed to be close to point U (Fig. 4). In general, a face centered cubic single crystal under tension will experience rotation towards the [001]-[111] line first and after that will rotate to [112] [47]. Polycrystalline specimens may demonstrate a more complex behavior, with the [001]-[111] line as an intermediate target. Pang et al. have conducted in-situ testing with 316L specimens using 3D X-ray micro-diffraction [47]. For a set of grains, their orientations were measured before and after straining to 8\%. It was shown that most grains, in general, demonstrated the expected behavior: rotation to the [001][111] line with [112] point as a stable final orientation. However, a few grains rotated towards the [001]-[101] boundary. Such deviation was explained by local constraints due to the interaction with neighboring grains. 


\subsection{Structure of deformed specimens}

\subsubsection{Specimen D1-2}

Fig. 5 shows the gauge of specimen D1-2 and presents the corresponding EBSD data. Large grains are clearly visible, as well as a significant level of misorientation within these grains. Color changes (see the color key in Fig. 1) suggest an internal misorientation level of $\sim 20-25^{\circ}$, with relatively smooth transitions. Patterns were taken at numerous locations inside the large grains and analyzed in hand-mode, making sure the phases were identified correctly.

Interestingly, regular grains in the non-deformed portion of the gauges demonstrated practically no in-grain misorientation; their structure was typical for annealed austenite. Mechanisms leading to the formation of such structure are still somewhat unclear and will be addressed in future studies.

As local strain increases to levels of $\sim 30 \%$ or greater, low magnification scans became noninformative due to the large number of small-size features such as twins. Such an area with a highly fragmented structure is seen in Fig. 5 at the left. High-resolution (magnification 1500x, step size $0.1 \mu \mathrm{m}$ ) EBSD scans for some highly deformed areas ( 70\% or more) of D1-2 specimen (locations A and B in Fig. 5) are shown in Fig. 6. Compared to TEM, EBSD is not able to image the defect structure such as dislocations, etc. directly. However, EBSD easily visualizes local misorientation gradients caused by dislocation density variations and irregularities such as phase or twin boundaries. For instance, the structure in Fig. 6 contains multiple deformation twins of $\sim 0.5-2 \mu \mathrm{m}$ width. Also, specific round-shaped austenitic areas with $5-20^{\circ}$ misorientation relative to the parent matrix are clearly visible (black dashed ovals) in Fig.6. Their size and appearance suggests that they might be dislocation cells, which were observed in the deformed material by TEM.

Reliably detected martensite particles have an elongated shape and size of $0.5-2 \mu \mathrm{m}$. The martensite amount at location A in Fig. 6 is larger compared to that at location B, and further increased as the scan location approached the fracture point. The phase map for the Location A was overlapped with IQ map to demonstrate that martensite formed mainly inside the most pronounced slip lines, which had lower EBSD pattern quality and thus darker color in the IQ map. Often martensite particles formed inside deformation twins or at twin-matrix interface. Martensite has a higher strength compared to the parent austenite and may lead to local hardening if the volume fraction of bcc-martensite is high enough.

Interestingly, only bcc-martensite ( $\alpha$-phase) was observed in the structure. No hcp-martensite ( $\varepsilon$ phase) was reliably detected, suggesting a direct transformation path (i.e. fcc $\rightarrow$ bcc). Depending on strain and stress levels, stress state, and material composition, both direct (fcc $\rightarrow$ bcc) and 
indirect (fcc $\rightarrow$ hcp $\rightarrow$ bcc) transformation paths may exist [48-50]. However, this aspect requires additional special investigation for irradiated materials involving in-situ step-by-step straining or a number of specimens deformed at different strain level [49].

Deformation twins were clearly visible in some moderate-resolution and many highmagnification (1,300-1,500x) scans. In the D7-2 specimen, the deformation twin density and geometry varied significantly from grain to grain, with many grains observed to be free of deformation twins. In most cases, the deformation twinning was the most pronounced in the grains oriented close to [111] relative to the straining direction, whereas the grains oriented closest to [001] and [101] were mostly twin-free.

\subsubsection{Specimen D6-2}

For the D6-2 specimen, low and moderate magnification scans (100-500×) with a step size of $\sim 1$ $\mu \mathrm{m}$ or more revealed a highly fragmented structure, but did not show any signs of regular size $(\sim 150-200 \mu \mathrm{m})$ grains. Therefore, taking into account the strain-induced relief, it appears that the neck portion (area N in Fig. 4) of the D6-2 specimen included one or two large grains that were subjected to fragmentation due to a high local strain level.

Fig. 7 shows a set of high-resolution EBSD scans for locations A-C identified in Fig. 4. Numerous twins were clearly identified in the structure, and the structure was similar to that of specimen D1-2 (Fig. 6), except that the amount of martensite observed was different. Specimen D6-2 had a higher amount of martensite compared to D1-2, and its martensite particles had significantly larger sizes, even though the local strain level for both specimens was roughly $\sim 70 \%$. The acting stress and the local strain values were similar for these specimens, suggesting there was another factor leading to the observed difference in martensite morphology. One important factor could be the orientation of the large grain, which will be discussed in the following sections.

The martensite amount $\left(\mathrm{V}_{\mathrm{a}}\right)$ increased from location $\mathrm{C}$ to location A with increase in the local strain. The maximum observed $V_{a}$ value reached $\sim 15 \%$, and the value is probably larger in the vicinity of the fracture point.

\subsubsection{Specimen D7-2}

Specimen D7-2 had a regular grain structure with average grain size of $\sim 150-180 \mu \mathrm{m}$. The deformed gauge had a relatively low uniform strain level ( 16\%) with magnetic phase amount of only $\sim 0.4 \%$. The neck portion contained more magnetic phase (Fig. 2) but no successful EBSDscans were performed for this portion due to low pattern quality. 
As follows from Fig. 8, the martensite particles form specific colonies (domains) consisting of 35 or more particles in the material with regular grain structure. Usually, the colony includes martensite particles of two different orientations relative to the parent austenite (Fig. 8). In specimen D1-2, martensite appeared as single particles and colonies were not observed. Specimen D6-2 contained both single particles separated in the structure and martensite colonies; the first dominated at smaller strain levels and the colonies appear to start at martensite amounts of $\sim 15 \%$.

All specimens demonstrated strong selection toward specific martensitic transformation variants. Although 24 different martensite orientations are possible in the austenitic matrix [48], only two or three were typically observed in the deformed material, and usually only one was dominant in the structure of any specific grain.

Fig 9 shows typical IPF plots for the three specimens. One can see the difference in the orientation of large grains in the D6-2 and D1-2 specimen; the main grain in the D1-2 specimen gauge had an orientation close to [112]. At a similar strain level, the D6-2 gauge contained much more martensite compared to specimen D1-2 (Fig. 7 vs. Fig. 6). Thus, it is possible to assume the orientation of specimen D6-2 was more favorable for martensite formation and allowed a faster transformation compared to specimen D1-2.

Additionally, it may be concluded that bimodal grain structure is the main factor responsible for the observed difference in the tensile behavior. No abnormal grains were observed in D7-2 specimen, and this specimen demonstrated no force drop in the small strain area and had a much higher tensile strength. It appears that the presence of abnormal grains in D1-2 and D6-2 led to the lower strength and larger elongation values.

\subsection{Role of grain orientation}

Specimen D7-2, at strain level of $\sim 16 \%$, had a very limited amount of martensite. Most grains were martensite-free; however, a few grains containing bcc-martensite were observed and these were analyzed. It is possible to expect that the gauge section of D7-2 was at the very early stage of the transformation. Thus, in spite of limited statistics, it is possible to select grains with the most favorable orientation toward martensitic transformation. The most pronounced martensite colonies are shown in Fig. 8, and Fig. 9 shows the orientation of the parent austenite grains containing the bcc-martensite. One can see that Grain \#1 is more transformed (dense colony of bcc-particles) than is Grain \#2 (small colony located close to grain boundary), so grain \#1 likely had a more favorable orientation to permit transformation.

Earlier, the role of grain orientation on the martensitic transformation was investigated for 
nickel-enriched AISI 304 stainless steel with grain size of $34 \mu \mathrm{m}$ [49]. The steel was subjected to both tensile and indentation deformation. It was shown [49] that, at the same stress and strain level, the average amount of martensite in a single grain increased if the grain orientation changed along the [111]-[311] line. The largest amount of martensite and the densest martensite colonies were observed mostly in grains oriented close to [310]. This orientation is close enough to the orientation of the Grain \#1 in D7-2 specimen (Fig. 8) and the large grain in D6-2 specimen (Fig. 4) that demonstrated unexpectedly high ductility. Interestingly, no martensite was observed in grains oriented close to [001] [49]. This observation agrees with the results published by other authors. For instance, Gey et al. [50] studied 304 steel tensile deformed at $-60^{\circ} \mathrm{C}$ to $10 \%$. They found that grains with [001]-orientation were less transformed compared to grains with [111]orientation. Thus, the phenomena of large deformation and deformation wave may not occur in a single grain specimen oriented close to [001].

Generalizing, it appears that in the irradiated 316L steel, the driving force of the martensitic transformation strongly depends on grain orientation. No transformation was observed in [101]oriented grains, and martensite tended to concentrate in grains oriented along the [001]-[111] line. The degree of transformation degree will increase with orientation change from [111] to $\sim[001]$, but in the present work no grains with exact [001]-orientation were found and analyzed.

Also, for a typical polycrystalline structure, only some grains will have an orientation favorable for the development of martensitic transformation, and among these grains, a very small fraction will have an orientation providing intensive martensite accumulation.

The large grain in specimen D6-2 had a favorable (and probably, the most favorable) orientation to support the martensitic transformation. It is possible to expect that the relative stability of the 316L composition was overcome by a material volume fraction capable of intensive martensite accumulation. Due to the presence of large grains, specimen D6-2 demonstrated a specific S-like transition in the necking portion of the curve (Fig. 1), a behavior typically observed during wave propagation.

For single crystal specimens, the critical stress value required to initiate the martensitic transformation is also sensitive to the grain orientation. For instance, Kireeva and Chumlyakov [51] investigated martensitic transformation in single crystals of austenitic alloys deformed at $77 \mathrm{~K}$; the composition of the alloy (wt.\%) was Fe-17Cr-12Ni-2Mn-0.75Si. It was found that the critical stress of austenite-to-martensite (fcc $\rightarrow$ bcc) transformation, according to electron microscopy results, varied significantly depending on crystal orientation. The lowest stress (430 $\mathrm{MPa}$ ) was observed for the [123]-orientation, which is close to the orientation of the abnormal grain in the D1-2 specimen. The [011]- and [111]-orientation demonstrated the modest stress levels (680-700 MPa) [51]. The exact [001]-orientation had a very high critical stress of 1000 MPa. Surprisingly, the crystal with a [012]-orientation had the highest critical stress level (1280 
MPa). Therefore, it might be concluded that grains of exact [001], [011], and [111]-orientations may be more stable compared to grains oriented close to the center of the unit triangle.

Deformation behavior of single crystal specimen strongly depends on its orientation relative to the load axis [51, 52]. At the same time, even bi-crystal specimens will demonstrate more complex behavior than will single crystal specimens [53]. Moreover, radiation-induced effects cause some deformation stages in a single crystal specimen to disappear [54]. In the present work our specimen included both large and regular grains; thus, the grain size and grain orientation effects overlapped with radiation damage and phase (martensitic) and structure (twinning) transformations leading to additional complexity. These aspects are clearly recognized in this work and will be addressed in the next work that will include in-situ analysis tools and methods like digital image correlation.

Finally, it should be noted that the large grain sizes may be responsible for the relatively large data scatter for elongation observed in the earlier study [21]. Both large grain size and orientation of the dominating grain should influence the behavior. When miniature-size tensile specimens are used, and especially if the grain size is of comparable magnitude to the gauge width, the chance orientation of a large grain strongly influences the onset of martensite transformation. Different orientations develop martensite at different rates and magnitudes, leading to differences in the tendency to form traveling deformation waves.

\section{Conclusions}

It was shown that anomalously large, out-of-specification, grain sizes existed in the head and gauge sections of some irradiated tensile specimens from the second operational SNS target module, sizes often comparable to the width of the gauge section. It appears that the differences in observed tensile behavior not only in the specimens examined in this study, but also most likely in the larger tensile data base, arose from previously identified mechanisms whose impact is amplified by the anomalously large grain sizes found in the steel used to build the SNS Target 2. The previously identified mechanisms are the radiation-induced hardening of stainless steels, the deformation twinning, the tendency of 300 series stainless steels to form martensite during deformation, and the acceleration of deformation-induced martensite with radiation.

The tendency to form martensite was shown to increase with increasing local strain, and with increasing grain size, and especially to be strongly dependent on grain orientation. Thus, specimens with nominally similar irradiation history can exhibit very dissimilar tensile behavior, depending only on the presence and random orientation of large grains in the gauge. Larger grains with most favorable orientation will generate the most martensite during straining and can advance to the "traveling deformation wave" regime. Less favorably oriented grains will exhibit less martensite formation and produce more typical radiation-hardened behavior. 


\section{Acknowledgements}

This research supported by the U.S. Department of Energy, Office of Nuclear Energy, for the Light Water Reactor Sustainability Research and Development Effort, and through a user project supported by ORNL's Center for Nanophase Materials Sciences (CNMS), which is sponsored by the Scientific User Facilities Division, Office of Basic Energy Sciences, U.S. Department of Energy. The authors would like to thank Dr. C.M. Parish (ORNL) for the discussion of the results, P.S. Tedder and A.M. Williams (ORNL) for the help with irradiated specimen handling.

This manuscript has been authored by the Oak Ridge National Laboratory, managed by UT-Battelle LLC under Contract No. DE-AC05-00OR22725 with the U.S. Department of Energy. The U.S. Government retains and the publisher, by accepting the article for publication, acknowledges that the U.S. Government retains a nonexclusive, paid-up, irrevocable, worldwide license to publish or reproduce the published form of this manuscript, or allow others to do so, for U.S. Government purposes.

\section{References}

1. F.A. Garner, "Radiation Damage in Austenitic Steels", in Konings, R.J.M., (ed.) Comprehensive Nuclear Materials, Volume 4, (2012) pp. 33-95, Elsevier.

2. L.K. Mansur, A.F. Rowcliffe, R.K. Nanstad, S.J. Zinkle, W.R. Corwin, R.E. Stoller, J. Nucl. Mater. 329-333 (2004) 166-172.

3. F.A. Garner, B.M. Oliver, L.R. Greenwood, M.R. James, P.D. Ferguson, S.A. Maloy, W.F. Sommer, J. Nucl. Mater. 296 (2001) 66-82.

4. B.A. Oliver. F.A. Garner, S.A. Maloy, W.F. Sommer, P.D. Ferguson, M.R. James, Proceedings of Symposium on Effects of Radiation on Materials, 20th International Symposium, ASTM STP 1405, ASTM, West Conshohocken, PA, 2001, pp. 612-630.

5. B. M. Oliver, M.R. James, F.A. Garner, S.A. Maloy, J. Nucl. Mater., 307-311 (2002) 14711477.

6. M.L. Hamilton, F.A. Garner, M.B. Toloczko, S.A. Maloy, W.F. Sommer, M.R. James, P. D. James. P. D. Ferguson, M. R. Louthan, Jr., J. Nucl. Mater., 283-287 (2000) 418-422.

7. B.H. Sencer, G.M. Bond, F.A. Garner, M.L. Hamilton, S.A. Maloy, and W.F. Sommer, J. Nucl. Mater., 296 (2001) 112-118.

8. S.A. Maloy, M.R. James, G. Willcutt, W.F. Sommer, M. Sokolov, L.L. Snead, M.L. Hamilton, F.A. Garner, J. Nucl. Mater. 296 (2001) 119-128.

9. S.A. Maloy, M.R. James, W.F. Sommer, W.R. Johnson, M.R. Louthan, M.L. Hamilton, F.A. Garner, Proceedings of Symposium on Effects of Radiation on Materials, 20th International Symposium, ASTM STP 1405, American Society for Testing and Materials, West Conshohocken, PA, 2001, pp. 644-659. 
10. Y. Dai, G.W. Egeland, B. Long, J. Nucl. Mater. 377 (2008) 109-114.

11. T.S. Byun, K. Farrell, E.H. Lee, J.D. Hunn, L.K. Mansur, J. Nucl. Mater. 298 (2001) 269279.

12. T.S. Byun, K. Farrell, E.H. Lee, L.K. Mansur, S.A. Maloy, M.R. James, W.R. Johnson, J. Nucl. Mater. 303 (2002) 34-43.

13. B.S. Li, Y. Dai, J. Nucl. Mater. 450 (2014) 42-47.

14. J. Chen, G.S. Bauer, T. Broome, F. Carsughi, Y. Dai, S.A. Maloy, M. Roedig, W.F. Sommer, H. Ullmaier, J. Nucl. Mater. 318 (2003) 56-69.

15. J. Chen, M. Rödig, F. Carsughi, Y. Dai, G.S. Bauer, H. Ullmaier, J. Nucl. Mater. 343 (2005) 236-240.

16. K. Farrell, T.S. Byun, J. Nucl. Mater. 296 (2001) 129-138.

17. D.A. McClintock, P.D. Ferguson, L.K. Mansur, J. Nucl. Mater. 398 (2010) 73-80.

18. D.A. McClintock, B.W. Riemer, P.D. Ferguson, A.J. Carroll, M.J. Dayton, J. Nucl. Mater. 431 (2012) 147-159.

19. B.J. Vevera, D.A. McClintock, J.W. Hyres, B.W. Riemer, J. Nucl. Mater. 450 (2014) 147162.

20. D.A. McClintock, J.W. Hyres, B.J. Vevera, J. Nucl. Mater. 450 (2014) 176-182.

21. D.A. McClintock, B.J. Vevera, B.W. Riemer, F.X. Gallmeier, J.W. Hyres, P.D. Ferguson, J. Nucl. Mater. 450 (2014) 130-140.

22. K. Farrell, E.D. Specht, J. Pang, L.R. Walker, A. Rar, J.R. Mayotte, J. Nucl. Mater. 343 (2005) 123-133.

23. L.N. Brewer, J.R. Michael, Microscopy Today, 18 (2010) 10-15.

24. D. Jorge-Badiola, A. Iza-Mendia, I. Gutierrez, Mater. Sci. Eng. A 394 (2005) 445-454.

25. M.N. Gusev, O.P. Maksimkin, I.S. Osipov, F.A. Garner, J. Nucl. Mater. 386-388 (2009) 273276.

26. M.N. Gusev, O.P. Maksimkin, I.S. Osipov, N.S. Silniagina, F.A. Garner, STP 1513, J. ASTM International, 6 (2010) 210-219.

27. M.N. Gusev, O.P. Maksimkin, F.A. Garner, J. Nucl. Mater. 403 (2010) 121-125.

28. G.N. Haidemenopoulos, N.Aravas, I.Bellas, Mater. Sci. Eng. A615 (2014) 416-423.

29. J.T. Stanley, L.E. Hendrickson, J. Nucl. Mater. 80 (1979) 68-78.

30. J. Morisawa, M. Otaka, M. Kodama, T. Kato, S. Suzuki, J. Nucl. Mater. 302 (2002) 66-71.

31. M.N. Gussev, J.T. Busby, L. Tan, F.A. Garner, J. Nucl. Mater. 448 (2014) 294-300.

32. D.L. Porter, J. Nucl. Mater. 79 (1979) 406-411.

33. D. L. Porter, F. A. Garner, G. M. Bond, Effects of Radiation on Materials: 19th International Symposium, ASTM STP 1366, American Society for Testing and Materials, 2000, pp. 884893.

34. P.J. Maziasz, J. Nucl. Mater. 205 (1993) 118-145.

35. R.M. Boothby, T.M. Williams, J. Nucl. Mater. 152 (1988) 123-138.

36. K.E. Knipling, D.J. Rowenhorst, R.W. Fonda, G. Spanos, Materials Characterization 61 (2010) 1-6. 
37. E. Johnson, L. Grabaek, A. Johansen, L. Sarholt-kristensen, P. Borgesen, B.M.U. Scherzer, N. Hayashi, I. Sakamoto, Nuclear Instruments and Methods in Physics Research B39 (1989) 567-572.

38. R.A. Dodd, F.A. Garner, J-J. Kai, T. Lauritzen and W.G. Johnston, Effects of Radiation on Materials: Thirteenth International Symposium (Part 1) Radiation-Induced Changes in Microstructure, ASTM STP 955, ASTM, Philadelphia, PA, 1987, pp. 788-804.

39. X. Chunchun, H. Gang, Anti-corrosion Methods and Materials 51 (2004) 381-388.

40. W.T. Tsai, J.R. Chen, Corrosion Science 49 (2007) 3659-3668.

41. J.K. Stanley, A.J. Perrotta, Metallography 2 (1969) 349-362.

42. T. McManamy, A. Crabtree, D. Lousteau, J. DeVore, L. Jacobs, M. Rennich, J. Nucl. Mater. 377 (2008) 1-11.

43. S. Mahalingam, P.E.J. Flewitt, J.F. Knott, Mater. Sci. (2012) 47:960-968.

44. J.C. Liu, J.W. Mayer, Nucl. Instrum. Meth. B(1987) 19/29:538.

45. G. Bregliozzi, A.D. Schino, S.U. Ahmed, J. Kenny, H. Haefke, Wear 258 (2005) 503-510.

46. Takeshi Iwamoto, Toshio Tsuta, Int.J.Plasticity 16 (2000) 791-804.

47. J.W.L. Pang, W. Liu, J.D. Budai, G.E. Ice, Acta Mater. 65 (2014) 393-399.

48. B. Petit, N. Gey, M. Cherkaoui, B. Bolle, M. Humbert, Int. J. Plast. 23 (2007) 323-341.

49. M.N. Gussev, T.S. Byun, J.T. Busby, C.M. Parish, Mater. Sci. Eng. A, 588 (2013), 299-307.

50. N. Gey, B. Petit, M. Humbert, Metallurgical and Materials Transactions A, 36A (2005), 3291-3299.

51. I.V. Kireeva, Yu.I. Chumlyakov, Mater. Sci. Eng. A 481-482 (2008) 737-741.

52. I. Karaman, H. Sehitoglu, H. J. Maier, Y. I. Chumlyakov, Acta Mater. 49 (2001) 3919-3933.

53. C. Rehrl, B.Volker, S. Kleber, T. Antretter, R. Pippan, Acta Mater. 60 (2012) 2379-2386.

54. M. Victoria, N. Baluc, C. Bailat, Y. Dai, M.I. Luppo, R. Schaublin, B.N. Singh, J. Nucl. Mater. 276 (2000) 114-122. 
Table 1. Chemical composition of specimens. Reproduced from the certified material test report (CMTR) for the heat of 316L used to fabricate the specimens.

\section{Composition (wt\%)}

\begin{tabular}{ccccccccc}
\hline $\mathbf{F e}$ & $\mathbf{C r}$ & $\mathbf{N i}$ & $\mathbf{M o}$ & $\mathbf{M n}$ & $\mathbf{S i}$ & $\mathbf{P}$ & $\mathbf{N}$ & $\mathbf{C}$ \\
\hline Balance & 16.850 & 10.190 & 2.090 & 1.500 & 0.510 & 0.024 & 0.060 & 0.024 \\
\hline
\end{tabular}

Table 2. Tensile properties of examined specimens.

\begin{tabular}{ccccccccc}
\hline Specimen & $\begin{array}{c}\text { Dose } \\
\text { [dpa] }\end{array}$ & $\begin{array}{c}\text { Yield } \\
\text { Strength } \\
\text { [MPa] }\end{array}$ & $\begin{array}{c}\text { Ultimate } \\
\text { Strength } \\
\text { [MPa] }\end{array}$ & $\begin{array}{c}\text { Fracture } \\
\text { Strength } \\
\text { [MPa] }\end{array}$ & $\begin{array}{c}\text { Fracture } \\
\text { Stress } \\
\text { [MPa] }\end{array}$ & $\begin{array}{c}\text { Uniform } \\
\text { Elongation } \\
{[\%]}\end{array}$ & $\begin{array}{c}\text { Total } \\
\text { Elongation } \\
{[\%]}\end{array}$ & $\begin{array}{c}\text { Reduction } \\
\text { in Area } \\
{[\%]}\end{array}$ \\
\hline D1-2 & 3.8 & 503 & 505 & 399 & 841 & 32.1 & 36.7 & 52.7 \\
D6-2 & 5.4 & 558 & 558 & 386 & 653 & 0 & 57.1 & 40.9 \\
D7-2 & 5.4 & 661 & 716 & 575 & 1173 & 24.1 & 31.9 & 51 \\
\hline
\end{tabular}

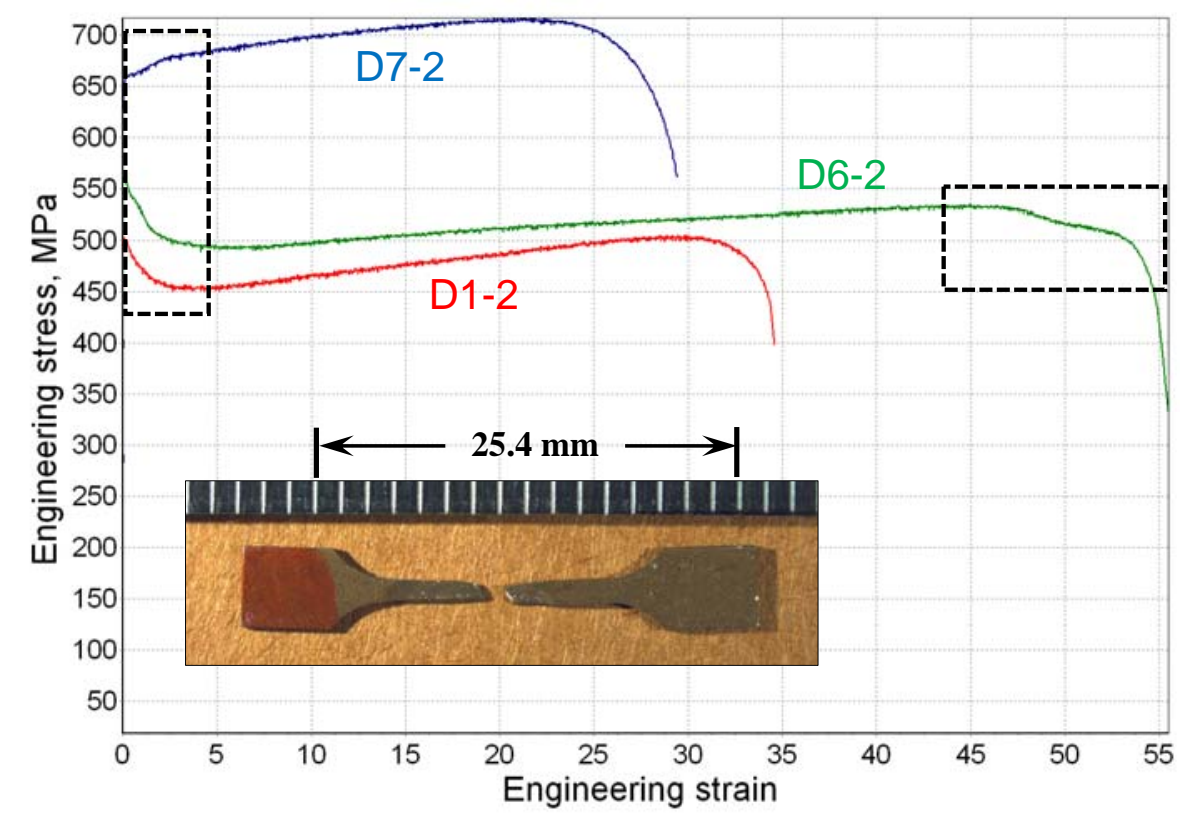

Fig. 1. Engineering tensile curves for the three examined specimens with the elastic strains removed. Dashed rectangles highlight specific details: force drop in two of the specimens (left) and complex behavior during necking (right). The insert photo shows the tested D6-2 tensile specimen with a rather elongated neck region. Red paint was used on one end of each specimen to maintain knowledge of the orientation with respect to the disk and target. D6-2 and D7-2 have the same dose, but D7-2 experienced somewhat lower temperatures. 


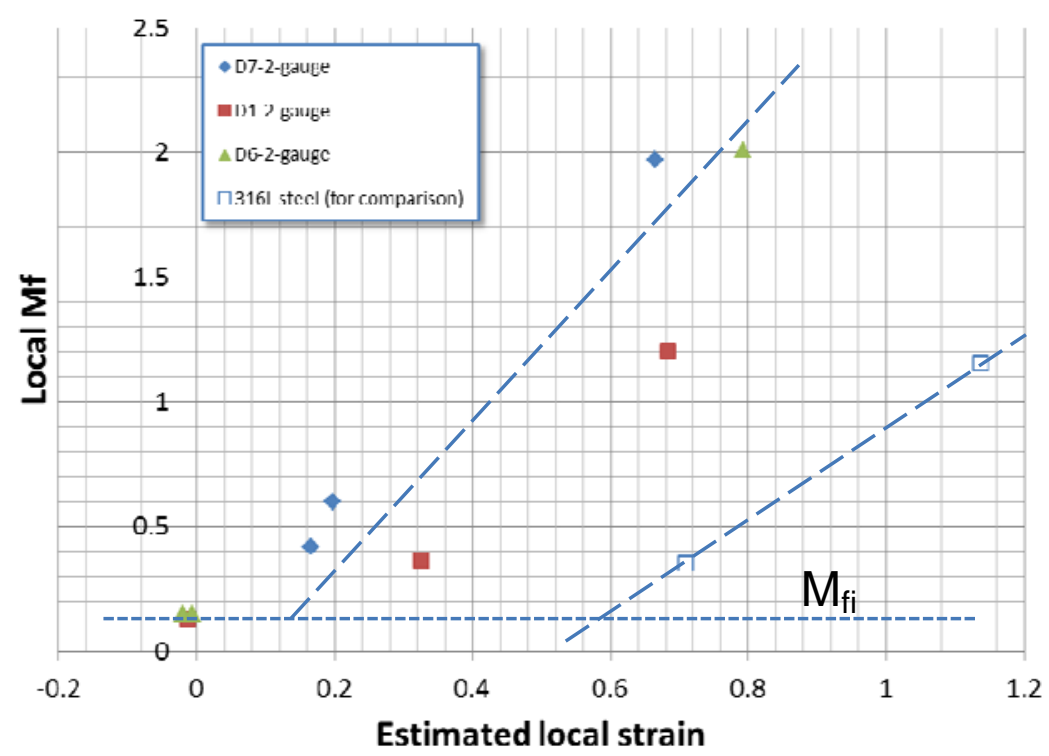

Fig. 2. Relative magnetic phase amount vs. local strain $\varepsilon_{\mathrm{L}}$ for the three examined specimens. Measurements on a nominally similar heat of non-irradiated commercial 316L steel are shown for comparison. The dashed horizontal line shows the relative level of magnetic phase induced by irradiation $\left(\mathrm{M}_{\mathrm{fi}}\right)$. 


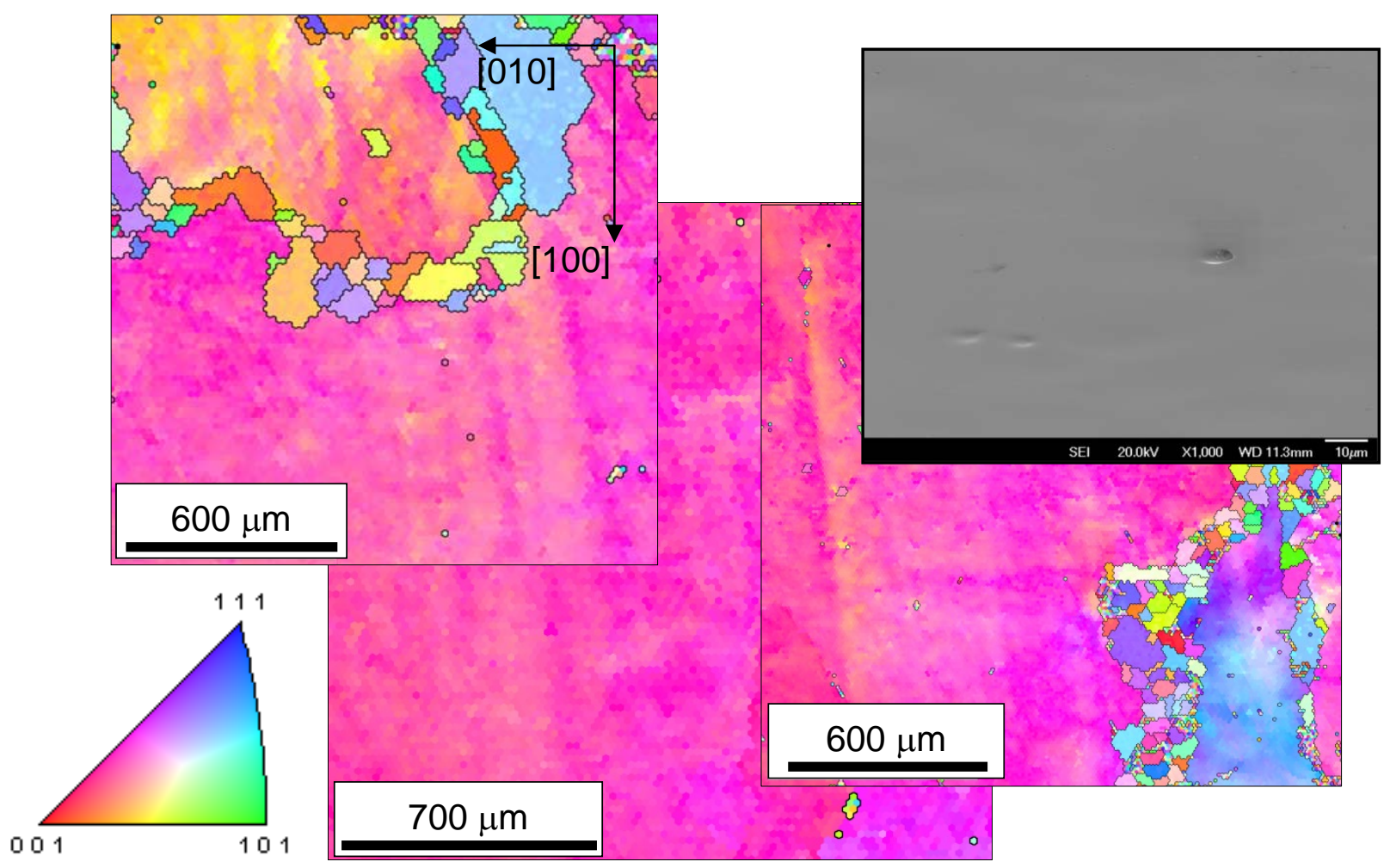

Fig. 3. IPF image of the non-deformed head of D6-2 tensile specimen. The color key at the lower left is the same used for all IPF-images throughout the paper. The overlapping EBSD scans demonstrate an abnormally large grain surrounded by a "necklace" of small grains. Variations in color within the large grain signal the presence of local variations in orientation. The SEM-image at the right shows the quality of the specimen surface and the very low density of non-metallic inclusions that were removed during polishing. 


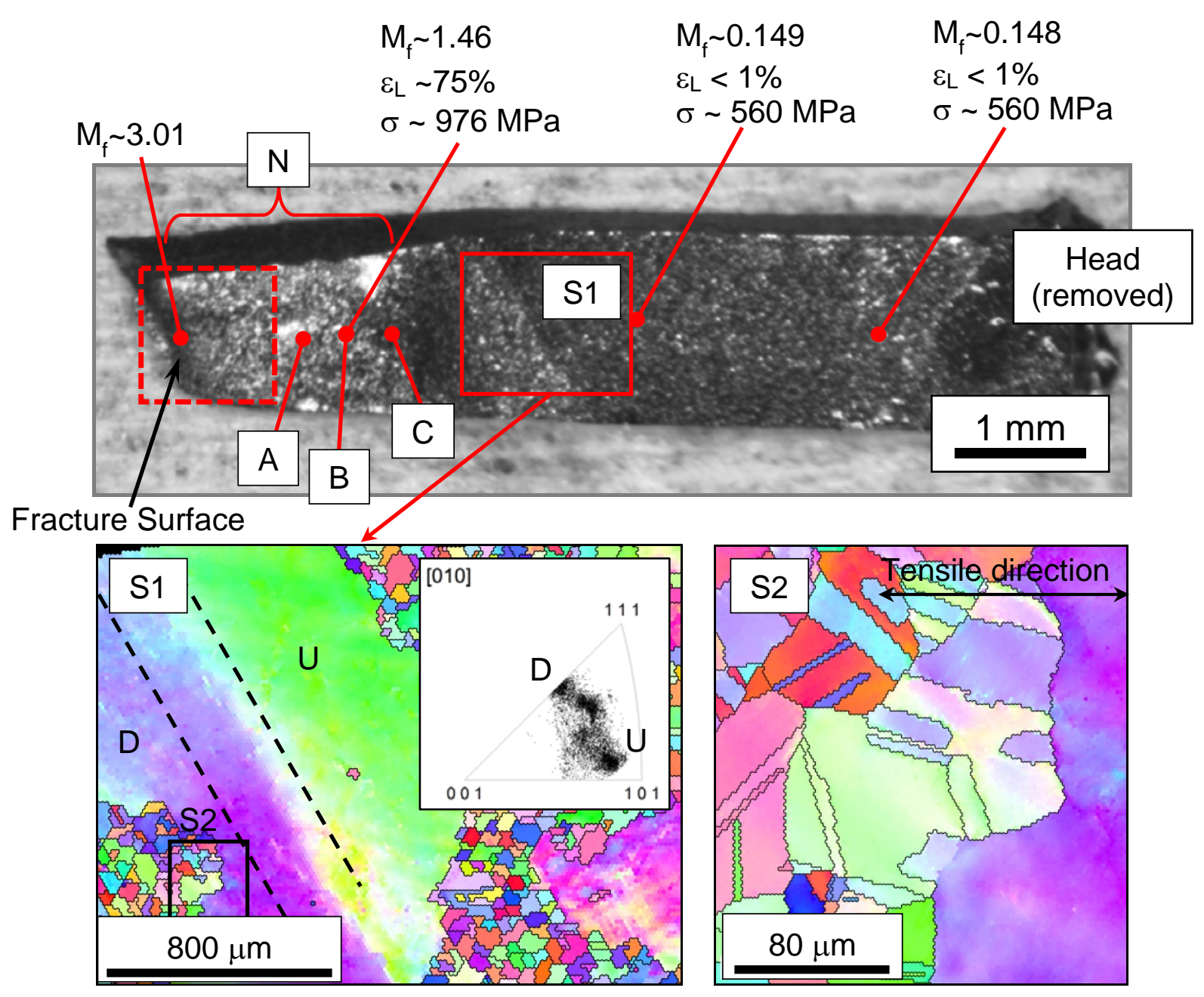

Fig. 4. D6-2 specimen gauge (view from the top) showing strain-induced relief peculiarities: pronounced deformation band (S1), and an elongated neck near the fracture surface (N). As surmised, areas $\mathrm{N}$ and $\mathrm{S} 1$ belong to grains with slightly different orientation. Local strain $\left(\varepsilon_{\mathrm{L}}\right)$ and true stress $(\sigma)$ values and magnetic phase amount (in relative units $\mathrm{M}_{\mathrm{f}}$ ) are also shown. A, B, C are EBSD-scan locations, shown in detail in Fig.7. No EBSD data were obtained for the neck area shown by the dashed rectangle due to low EBSD pattern quality. S1: EBSD-OIM data showing a large grain with pronounced misorientation; the insert shows an IPF-plot of this large grain. Locations U and D correspond to non-deformed and deformed areas, respectively. S2: subarea of S1-location scanned at higher resolution (see the color key in Fig.3). 


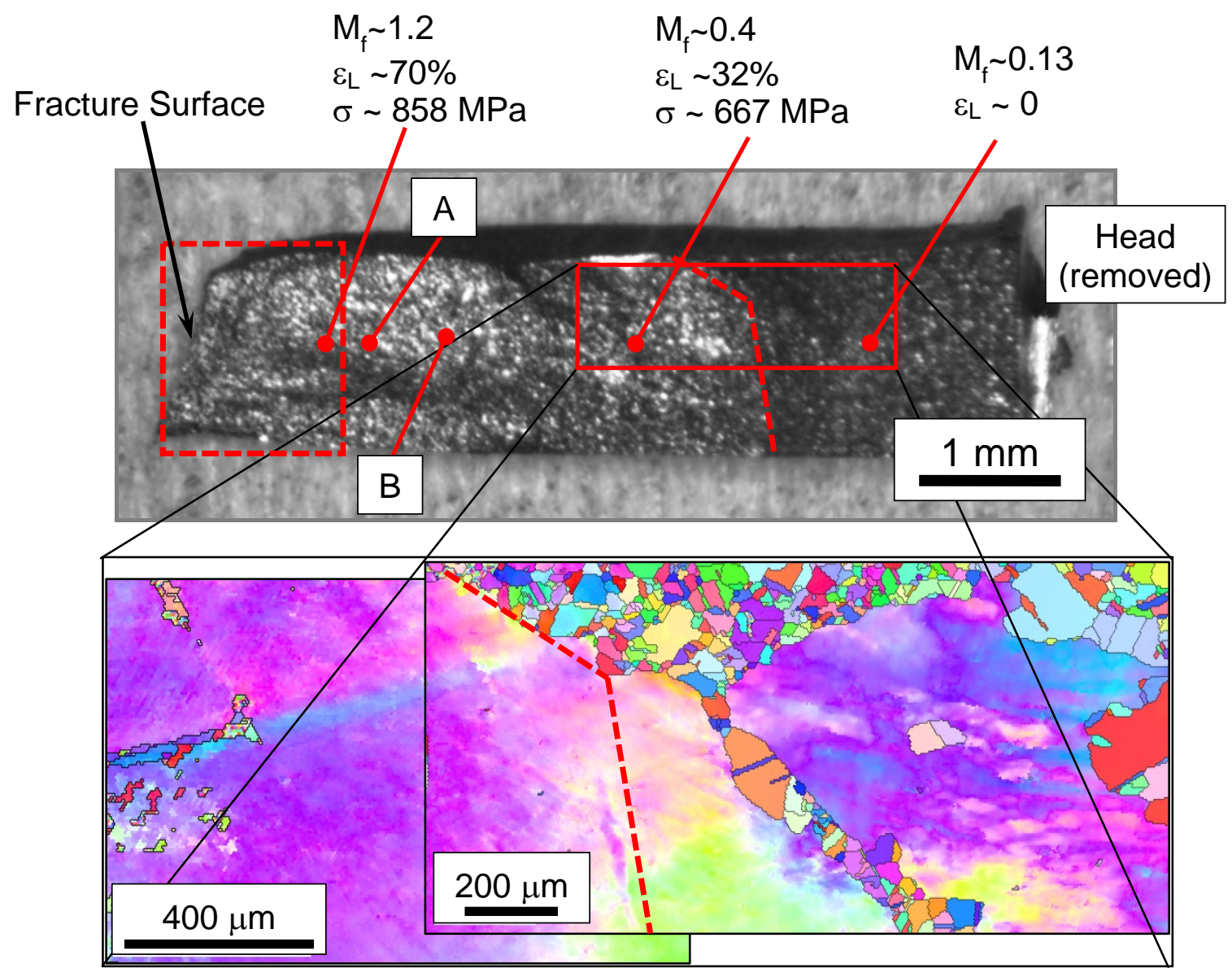

Fig. 5. Deformed gauge section of the tested D1-2 specimen (view from the top) and the corresponding structure for the area marked by the solid rectangle (see the color key in Fig.3). No EBSD data were obtained for the neck area shown by the dashed rectangle due to low EBSD pattern quality. 

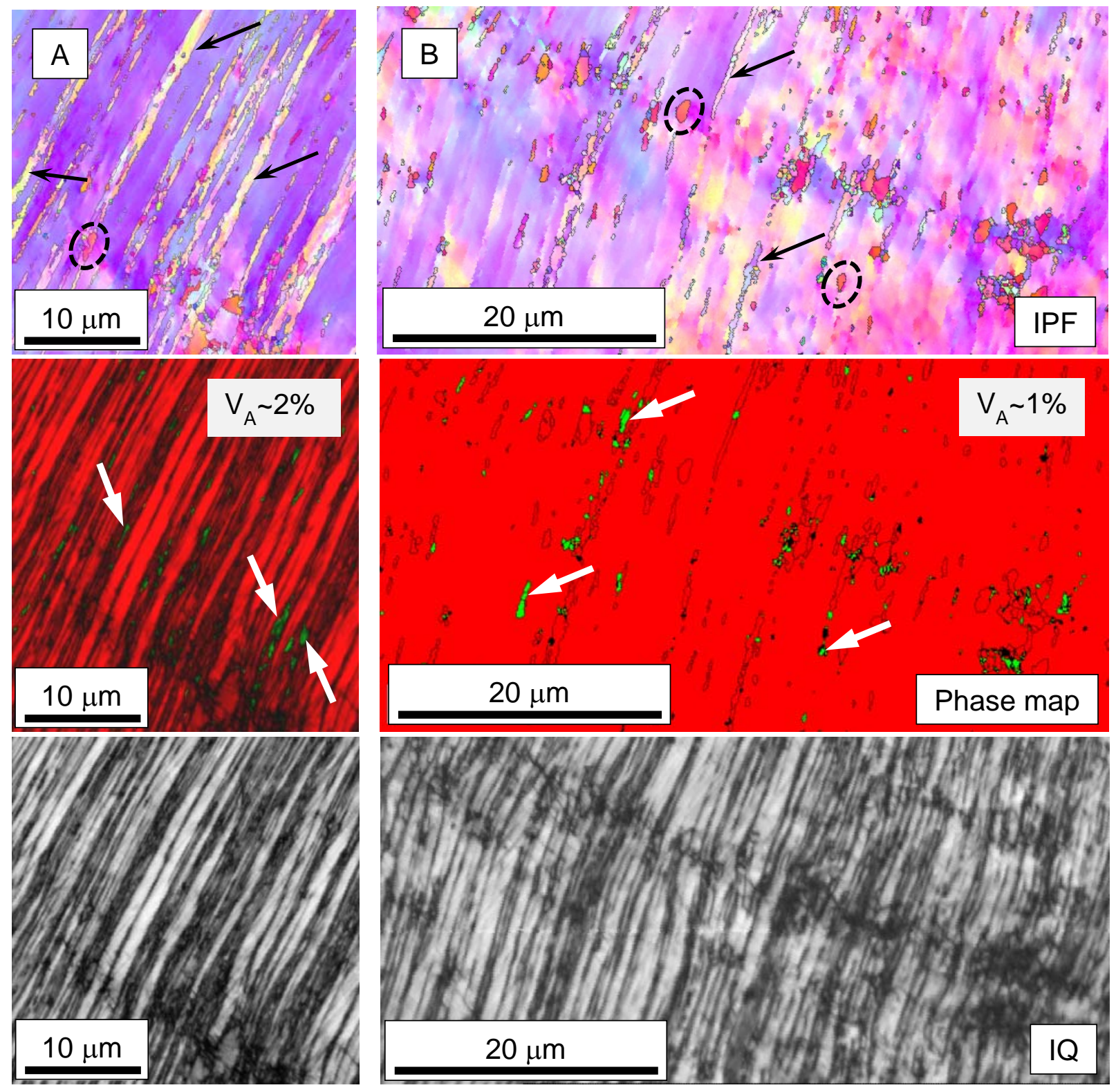

Fig. 6. Structure of D1-2 specimen; locations A and B (see Fig. 5 for detail). For each location, the [010]-IPF map (see the color key in Fig.3), Phase Map (red - austenite, green - bccmartensite), and Image Quality map are given. Black arrows show deformation twins and white arrows point to strain-induced martensite. No epsilon-particles were reliably identified. Local strain level was $\sim 70 \%$ at location A (less for B). Black dashed ovals surround specific roundshaped austenitic areas (not twins) with 5-20 misorientation relative to the parent matrix. 

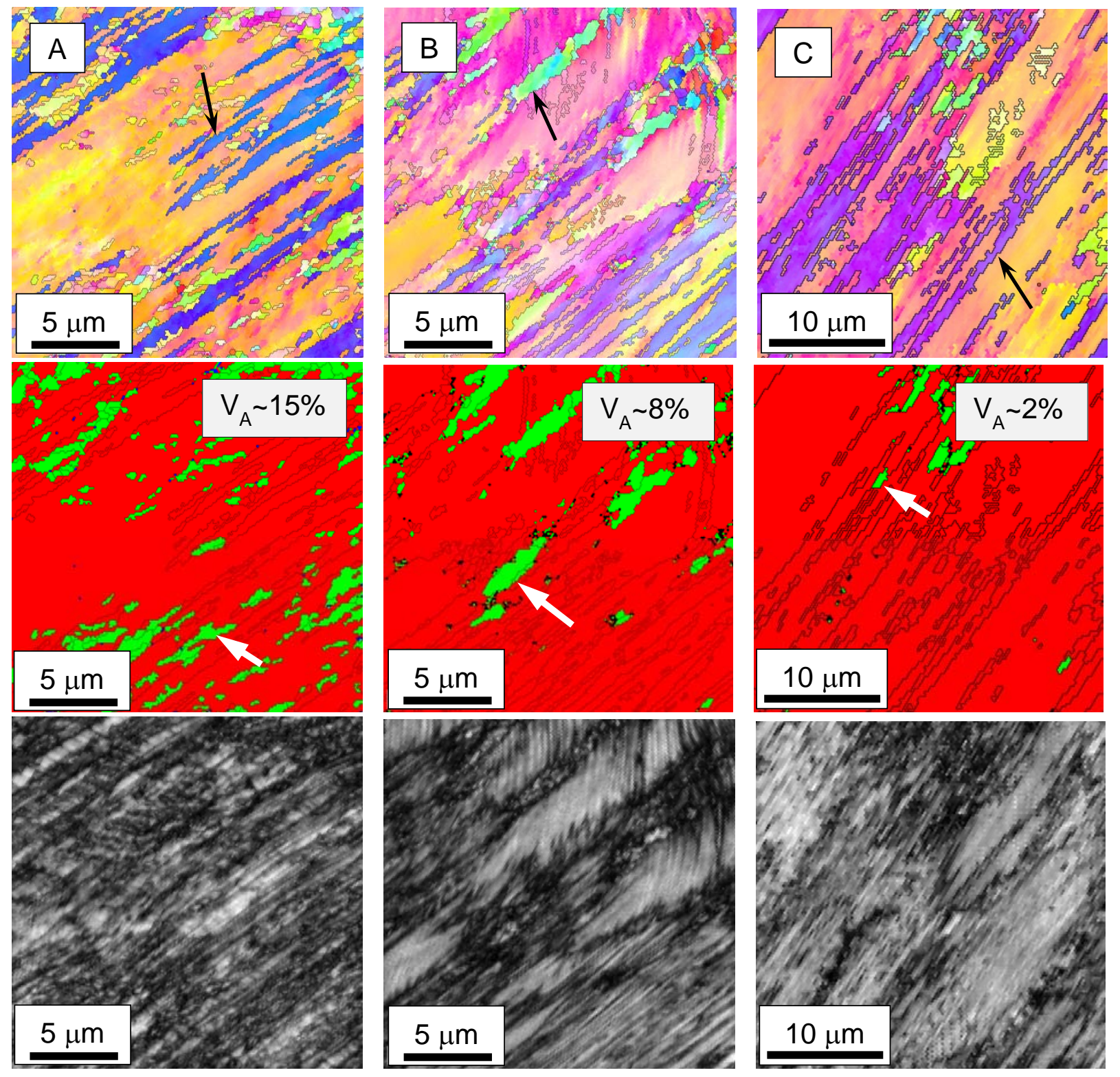

Fig. 7. Structure of D6-2 specimen; locations A, B, and C (see Fig. 4 for detail). For each location, the [010]-IPF map ([010] is the tensile direction, see the color key in Fig.3), Phase Map (red - austenite, green - bcc-martensite), and Image Quality map are given. Black arrows show deformation twins and white arrows point to strain-induced bcc-martensite. No epsilon particles (hcp-martensite) were reliably identified. Estimated local strain level increased from $\mathrm{C}$ to A with $\sim 75 \%$ strain observed at location B. 

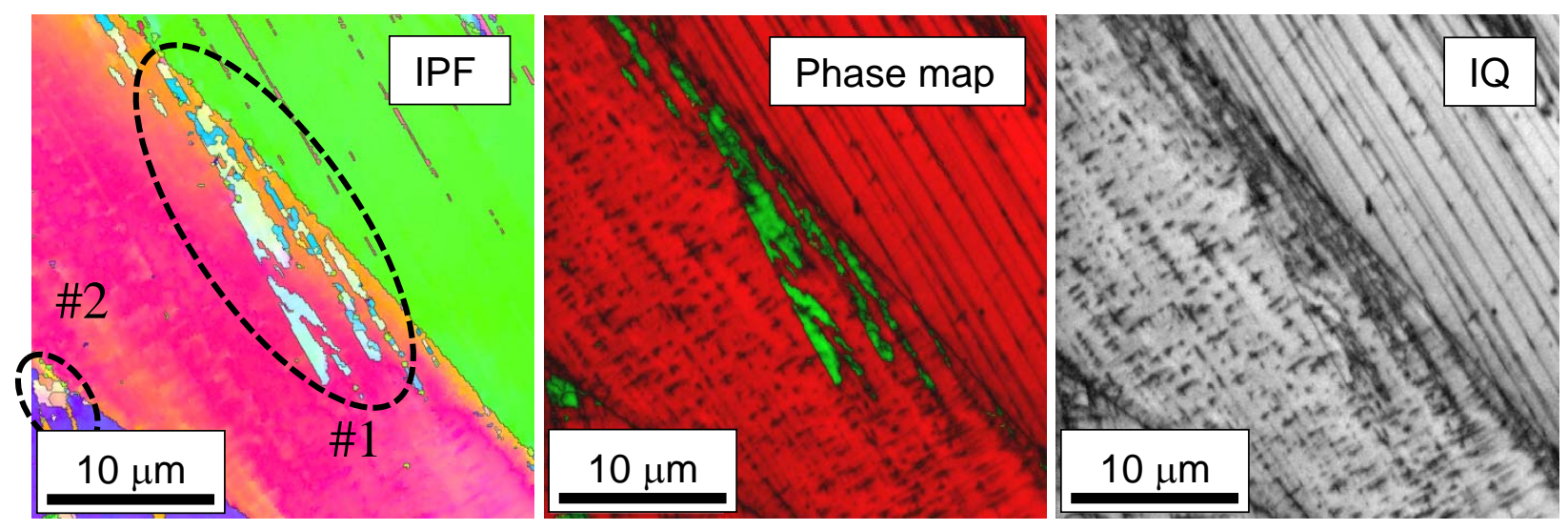

Fig. 8. Typical high-resolution ( $0.1 \mu \mathrm{m}$ step) EBSD scan data for the D7-2 specimen. Black dashed ovals surround martensite colonies in the [010]-IPF map. ([010] is the tensile direction, see the color key in Fig. 3). Austenite is red, and martensite is green in the Phase Map. No epsilon-particles were reliably identified. Local strain level $\sim 16 \%$, true stress $\sim 830 \mathrm{MPa}$, and $\mathrm{M}_{\mathrm{f}}$ $\sim 0.4 \%$. Areas \#1, \#2 are grains with pronounced martensite colonies (see also Fig. 9).

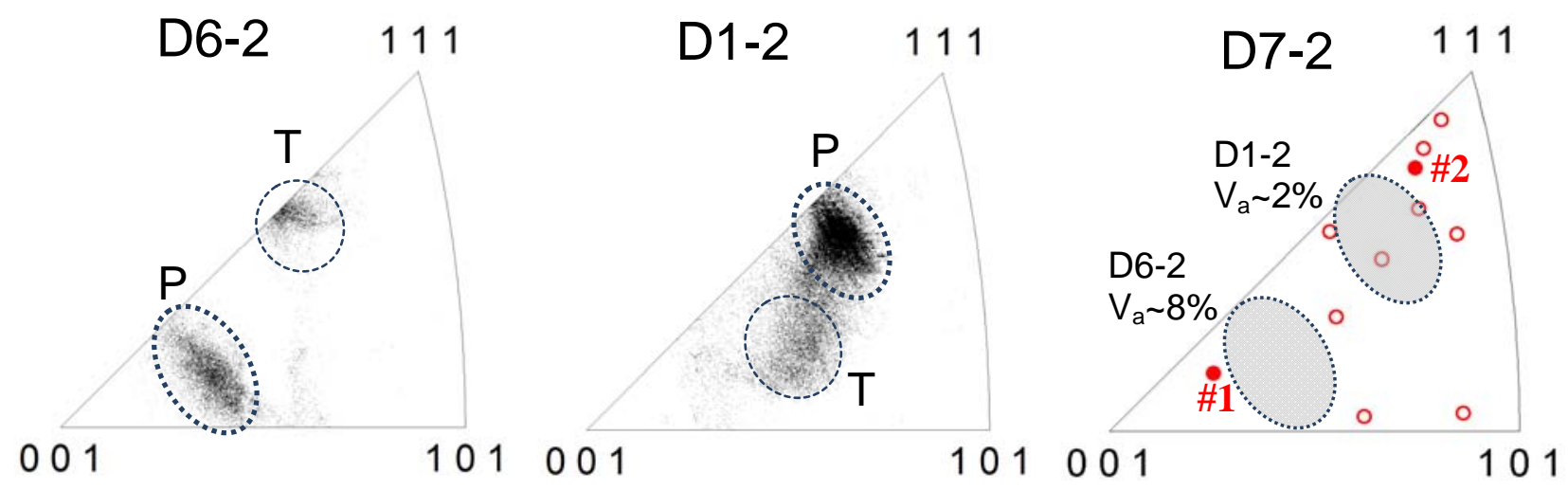

Fig 9. Typical [010]-IPF plots for the D6-2 and D1-2 specimens (data represent an average orientation of the large grains in the gauge) and cumulative [010]-IPF plot for the D7-2 specimen. [010] is the tensile direction. $\mathrm{P}-$ an average orientation of parent grain; $\mathrm{T}-$ orientation of the dominating deformation twins. D7-2 specimen: \#1, \#2 - orientation of austenite grains with martensite colonies shown in Fig. 8, empty symbols show orientation of martensite-free grains and filled symbols depict the orientation of grains with martensite colonies (Fig. 8). 